\title{
PSYCHOLOGICAL REGULARITIES OF CONSUMER CHOICE IN THE ECONOMIC BEHAVIOR OF PERSONALITY
}

\author{
Voskanyan K. V., Avanesyan H. M. (Yerevan State University, Yerevan, \\ Armenia) \\ voskanyankarlen@gmail.com,avanesyanh@ysu.am

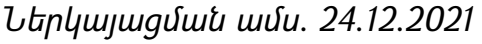

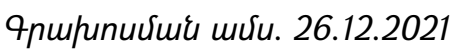

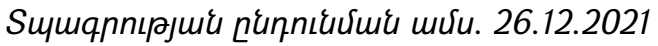

The article examines the problem of the economic behavior of an individual and analyzes the results of surveys aimed at identifying patterns created by psychological factors in the sampling process. To achieve this goal, a special questionnaire was developed, in which various situations of consumer choice are presented. 122 respondents took part in the survey, the average age of which was 32.6. This made it possible to assess the features of decision-making with some uncertainty. Issues related to the economic behavior of an individual, which have always been and remain the focus of attention of economic theories, have become the subject of interdisciplinary research. Research into the patterns of economic behavior, which is largely due to psychological factors, is especially relevant. Scientists, increasingly using mathematical methods, are building more realistic models of the economic behavior of an individual. In research in this direction, the goal is to find out how psychological characteristics and socio-psychological factors affect the economic behavior of an individual.

Keywords: economic behavior, personality, modeling, motives, choice, consumption, psychological factors.

DOI: https://doi.org/10.46991/SBMP/2022.5.1.133

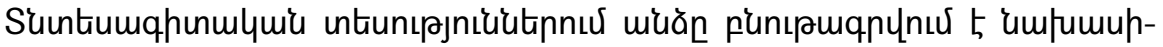

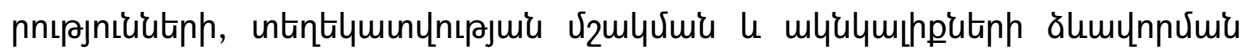

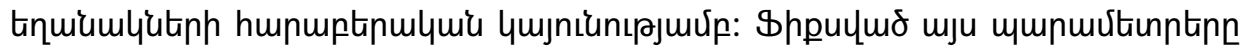

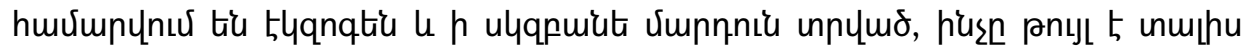

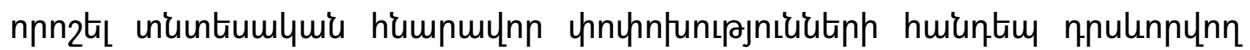

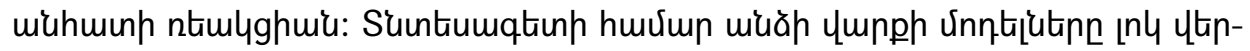

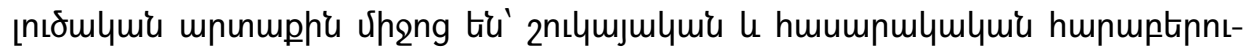

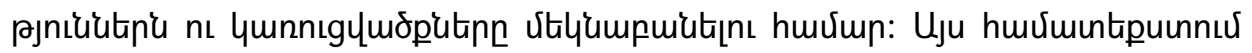

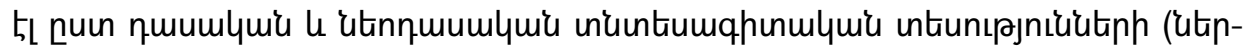

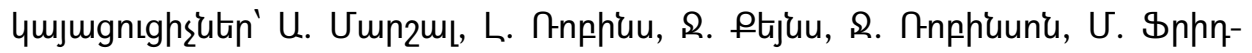




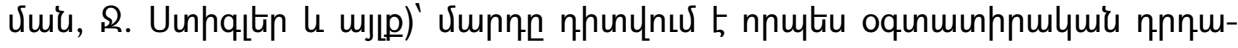

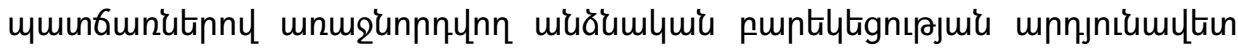

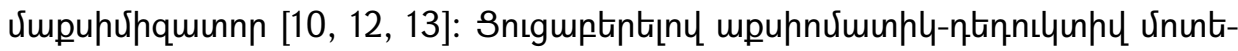

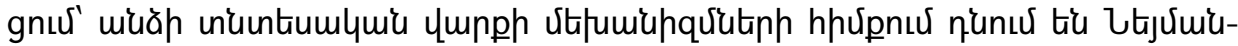

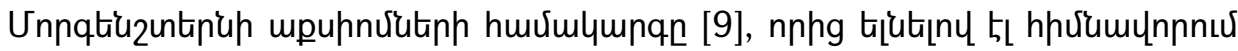

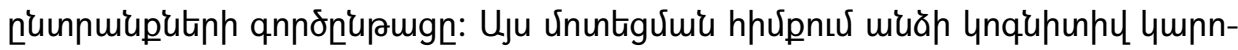

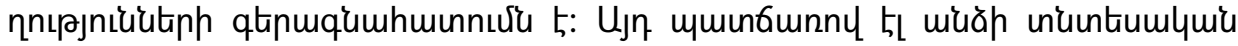

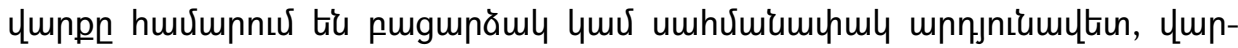

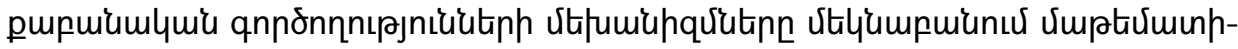
цmlymi hu2

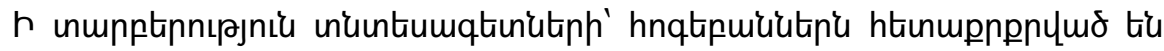

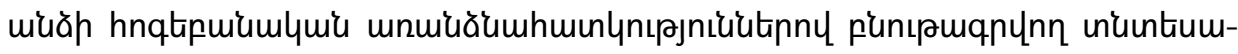

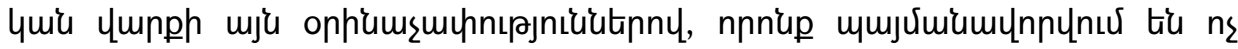

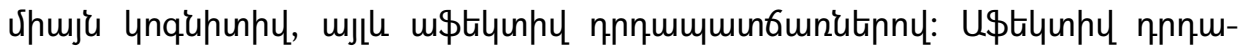

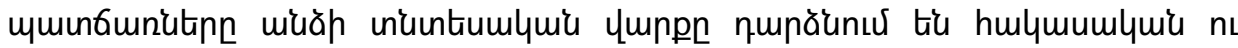

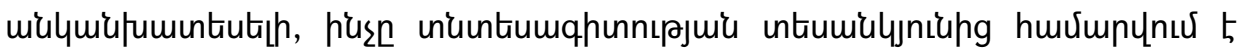

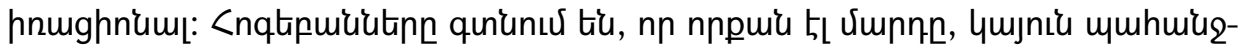

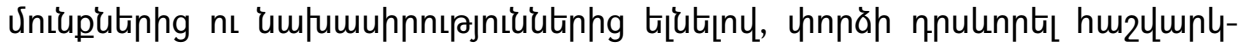

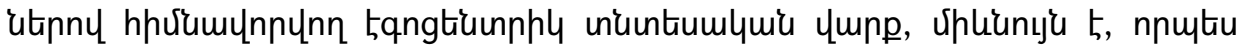

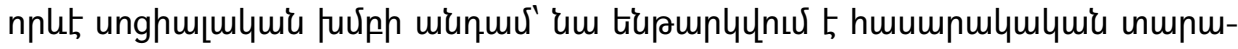

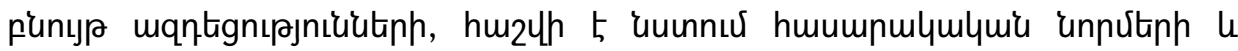

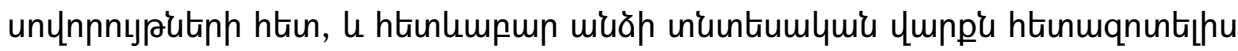

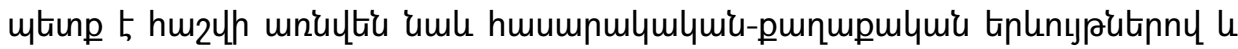

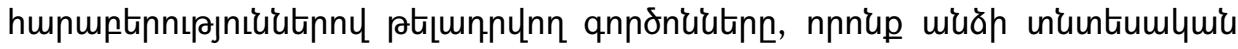

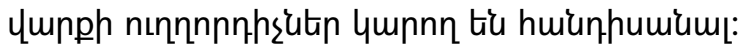

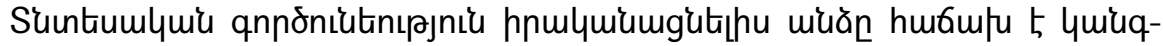

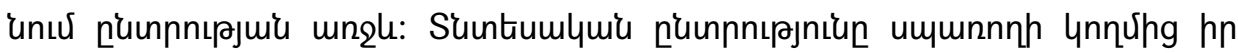

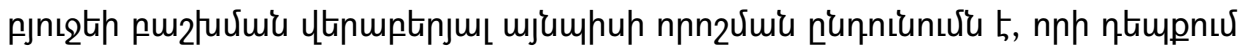

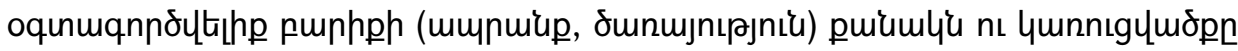

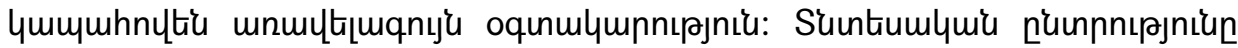

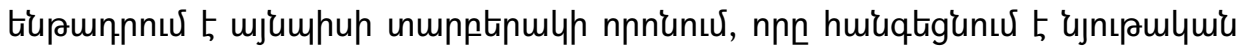

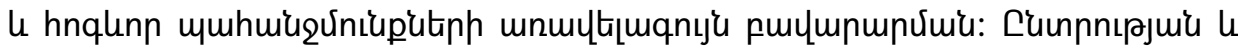

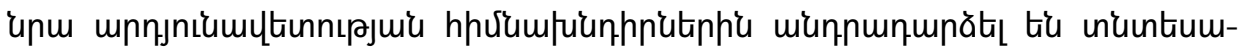

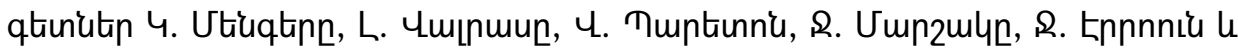

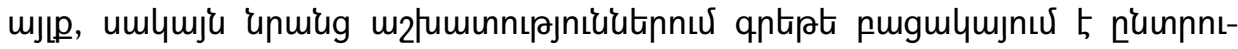

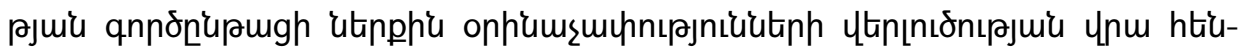
Ч

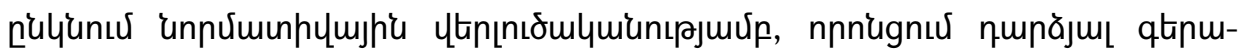

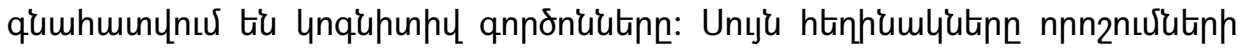

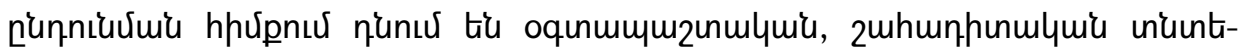




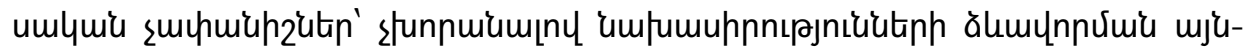

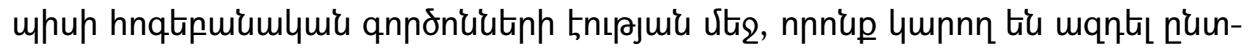

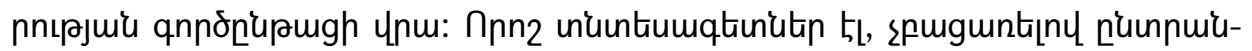

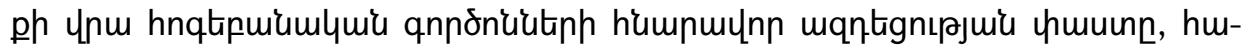

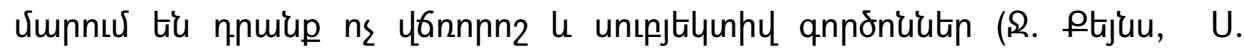
Lhütiuptinq):

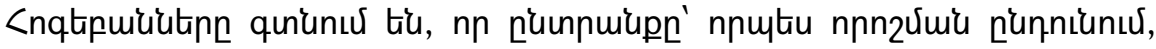

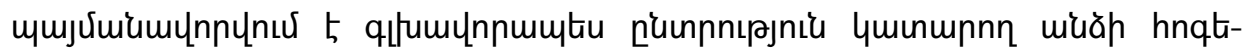

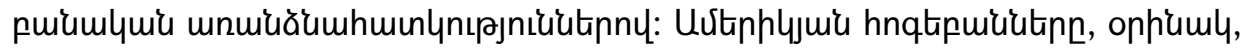

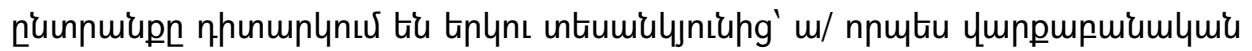

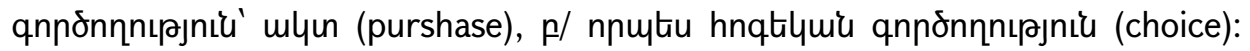

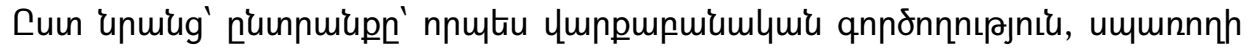

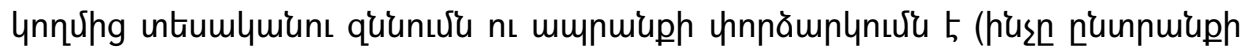

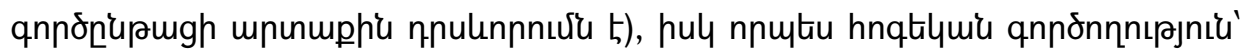

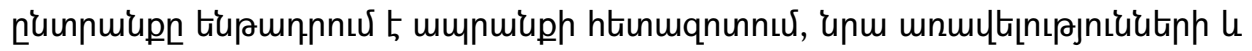

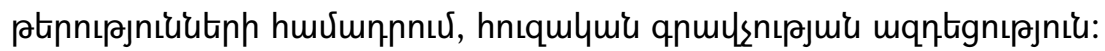

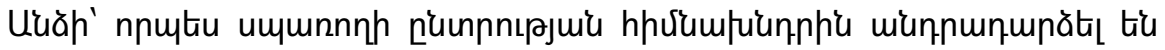

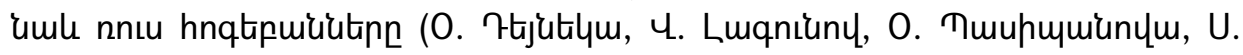

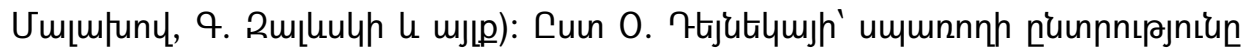

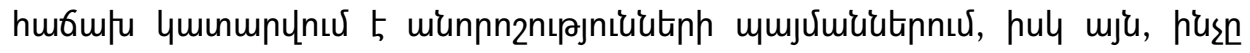

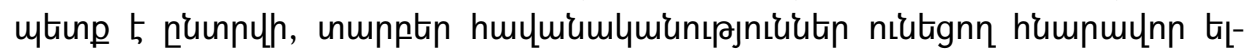

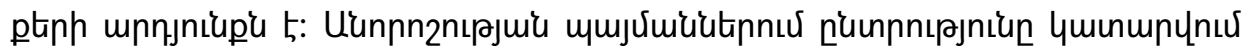

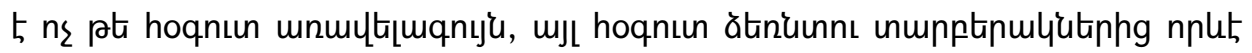

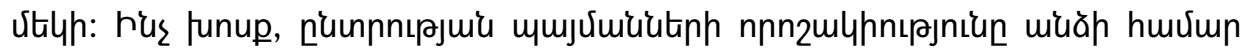

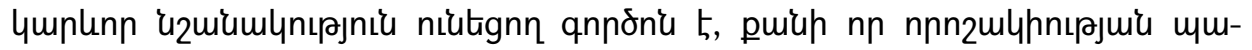

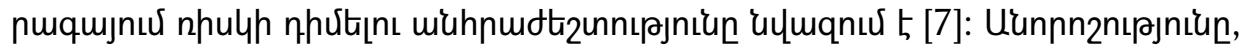

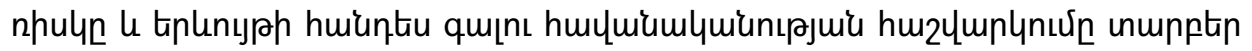

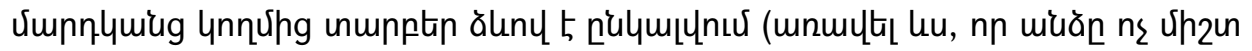

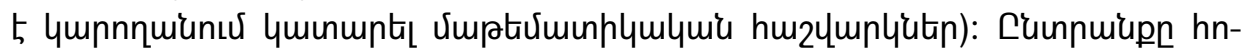

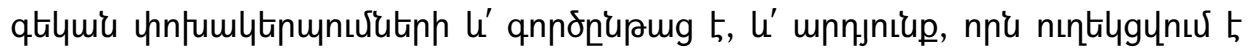

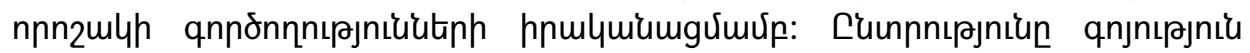

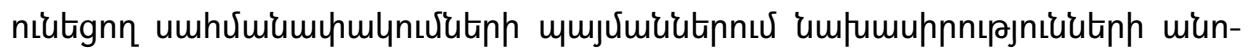

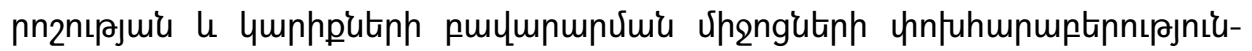

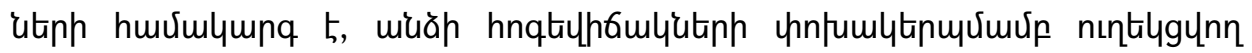
qnnon'upumg:

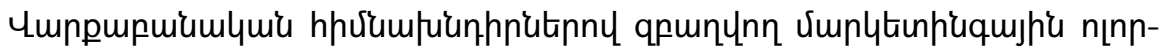

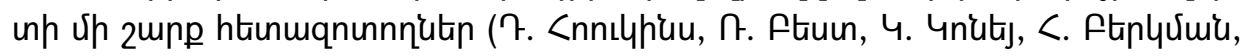

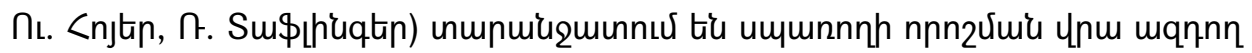

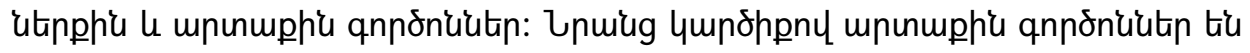

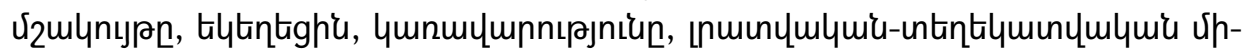




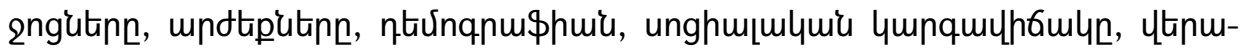

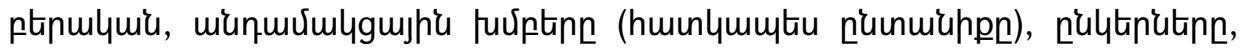

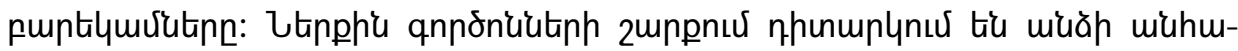

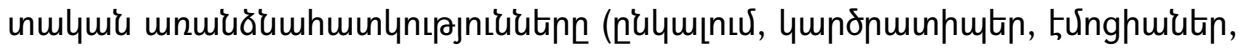

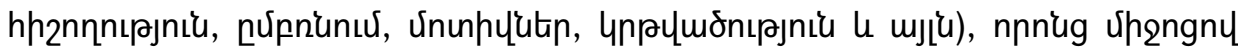

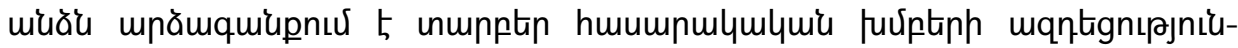

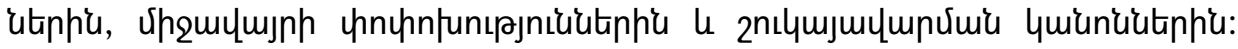

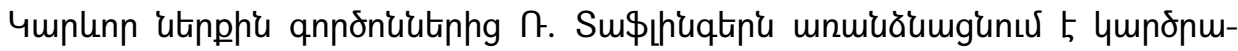

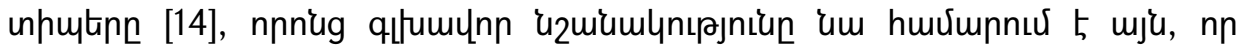

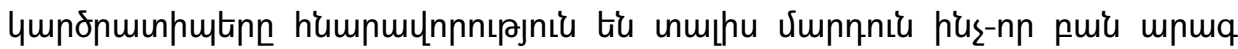

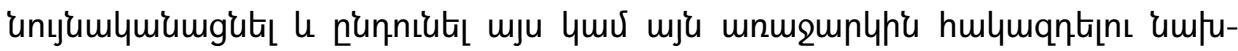
umlquí nnn2nux:

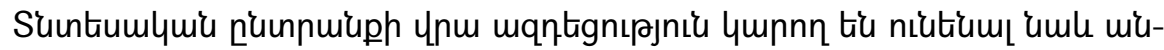

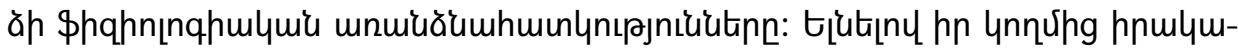

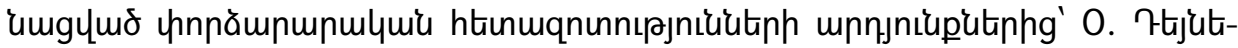

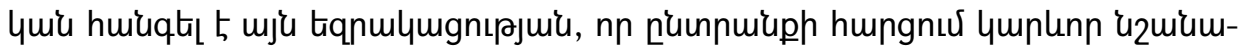

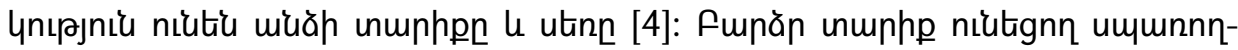

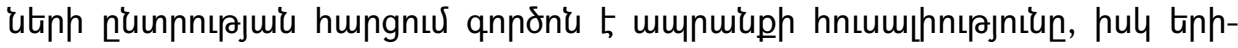

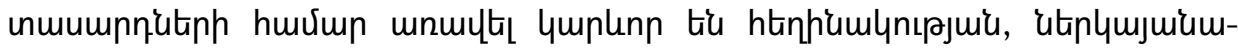

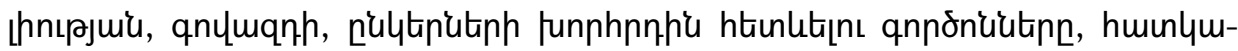

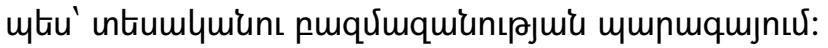

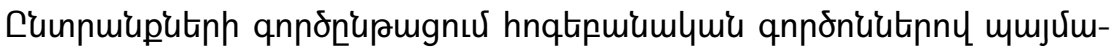

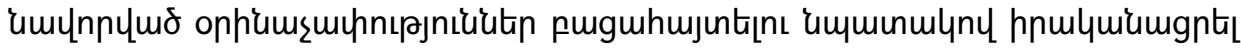

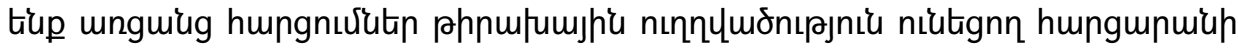

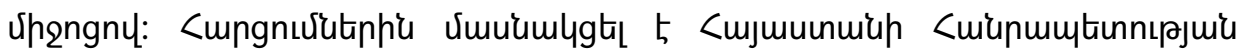

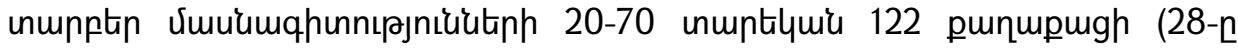

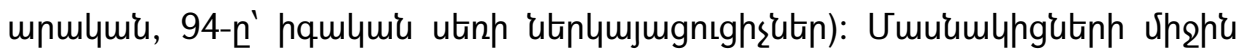

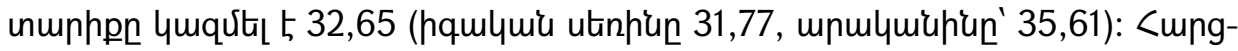

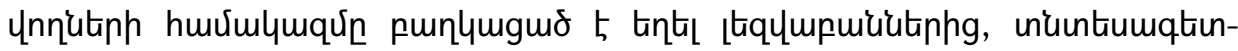

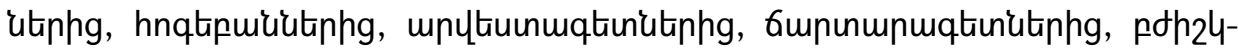

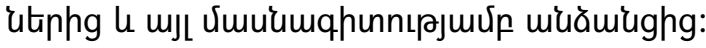

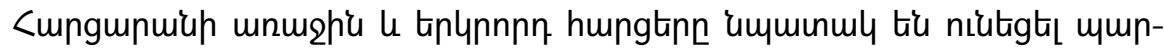

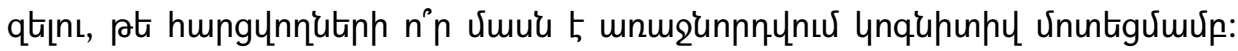

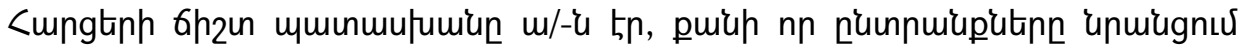
muthih unnpn thu:

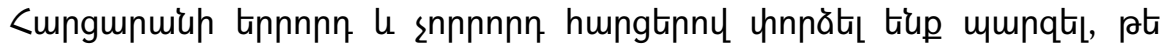

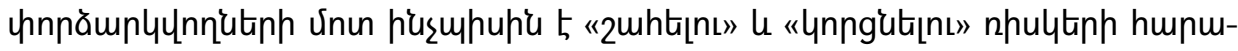

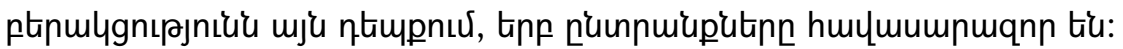

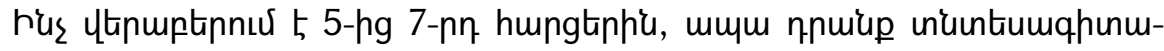

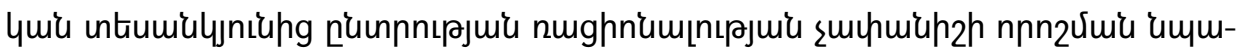




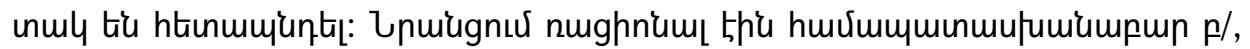
p/ l m/ n'unnmiuputinn:

\section{Unjniumly 1.}

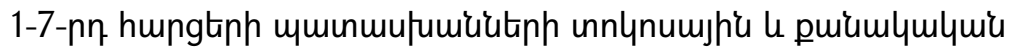

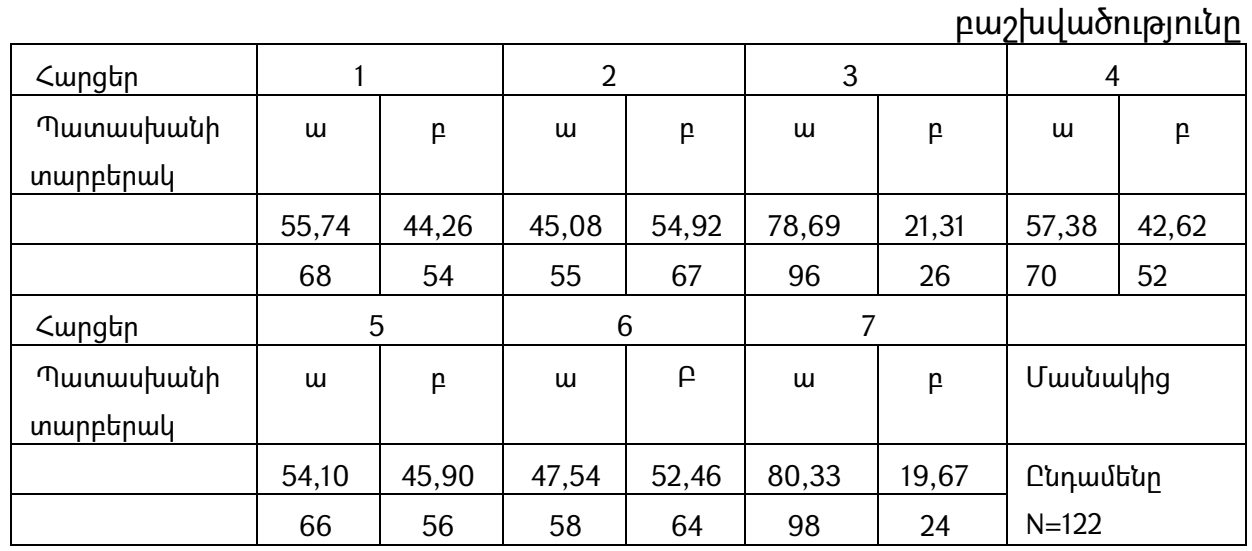

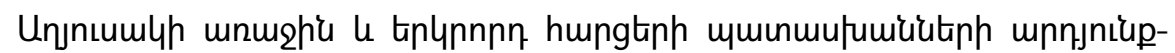

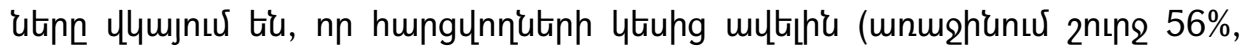

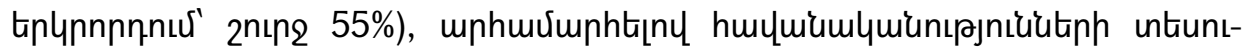

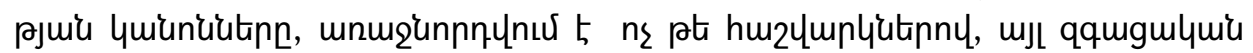

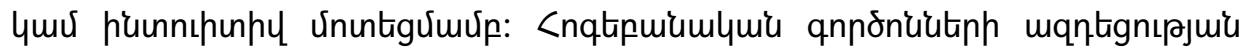
yun mumgnug tiu 'umle hungtiph w/ le p/ nunnuiuputitp 55,74\% \& 45,08\%

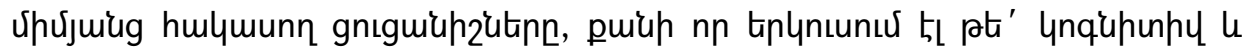

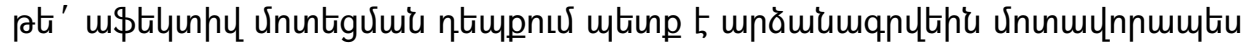

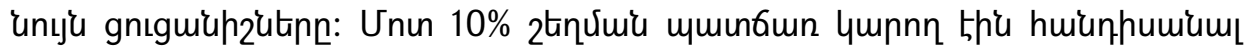

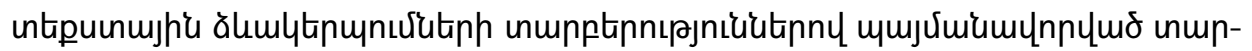

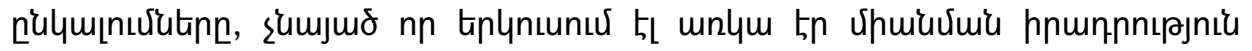

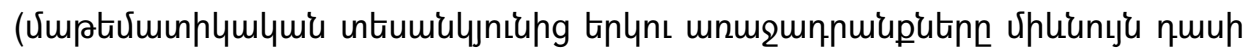

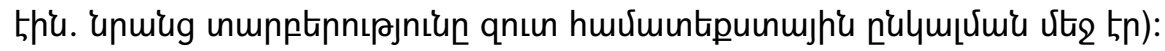

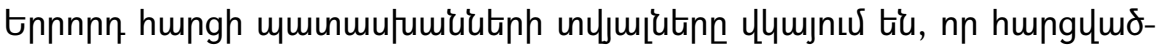

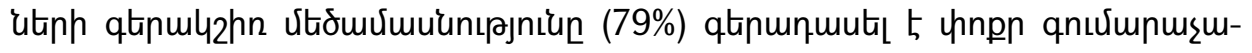

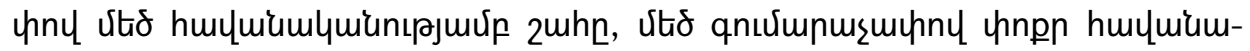

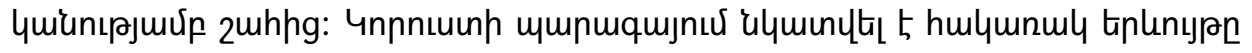
(hush Ч Ч

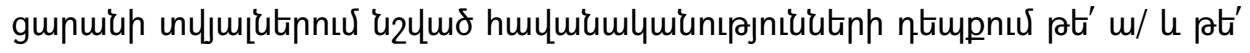

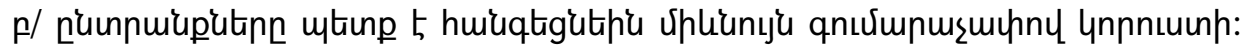

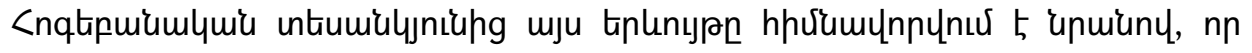

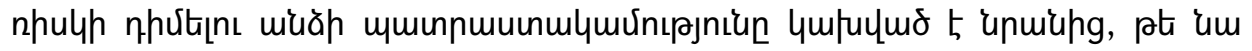

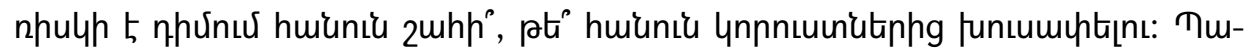




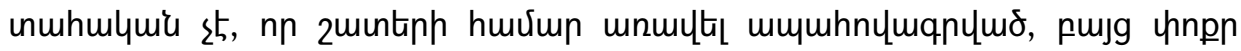

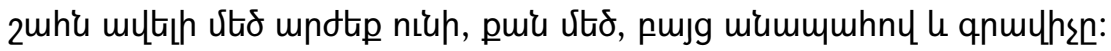

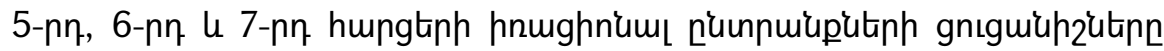

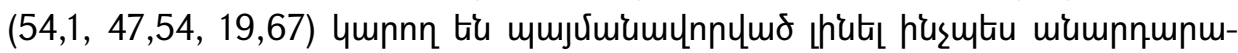

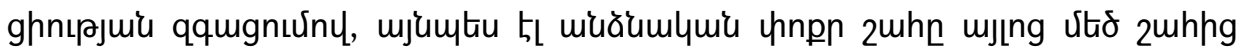

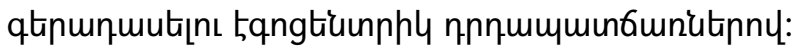

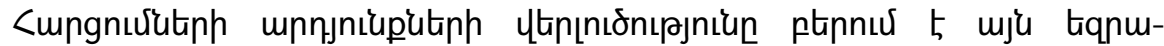

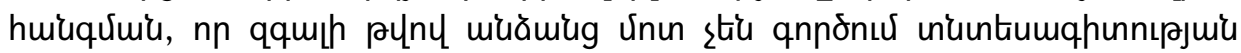

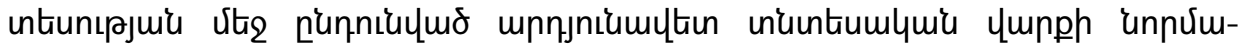

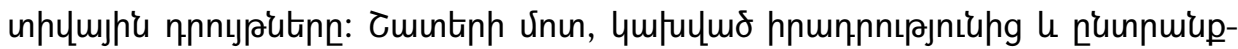

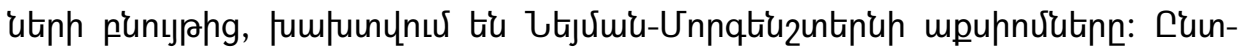

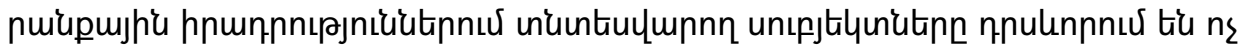

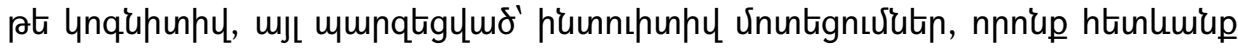

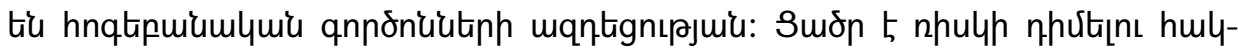

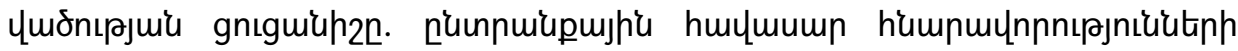

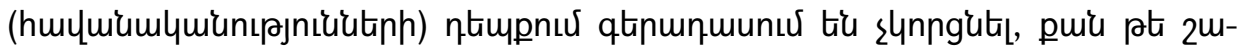

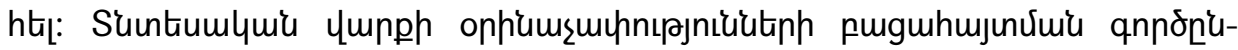

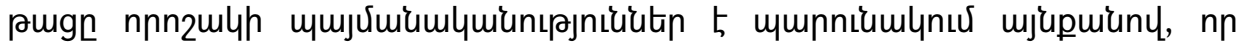

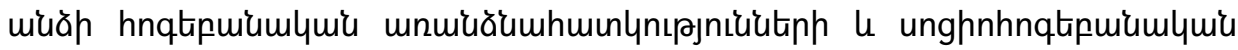

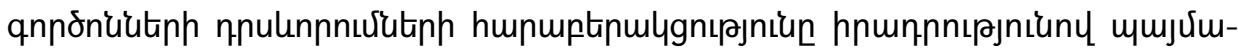

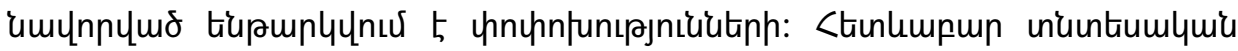

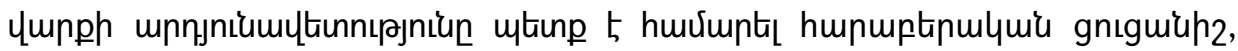

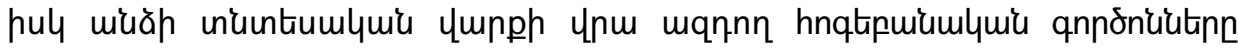

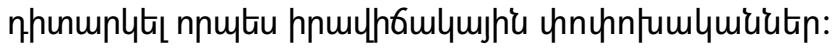

\section{9pulquínıpjnitu}

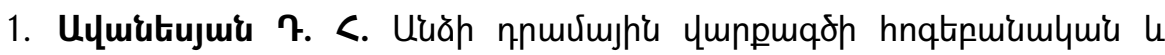

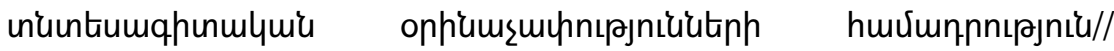

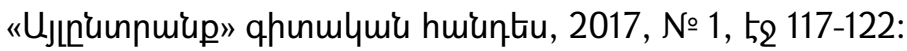

2. Upnqnjuir ч. U., Uupunpnnujuir $u$. ก. <nqtipuiunıpniu $u$

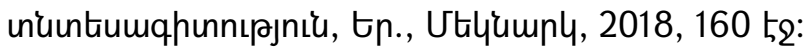

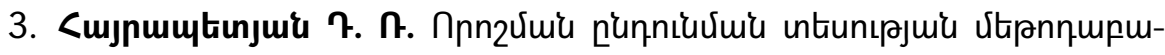

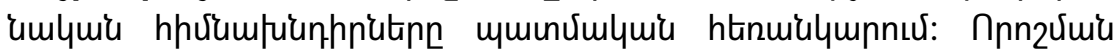

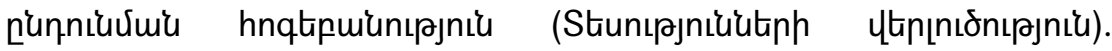

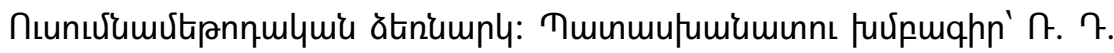
<ujnumbinjuiu. $\quad$ tp., $\quad \forall T<\quad$ hnuin., 2010 , 52 826.http://lib.ysu.am/disciplines_bk/4b337dfa763991ef7e8f4bd3f2ea6de3 .pdf (18.12.2021)

4. Дейнека О. С. Экономическая психология / Учебное пособие. СПбГУ, 2000. - 160 с. 
5. Залевский Г. В. Личность и фиксированные формы поведения. - М.: Институт психологии РАН, 2007. - 336 с.

6. Канеман Д., Словик П., Тверски А. Принятие решений В неопределенности: Правила и предупреждения. Харьков: Гуманитарный Центр, 2005. - 632 с.

7. Корнилова Т. В. Психология риска и принятия решений: Учебное пособие для вузов / Т.В.Корнилова. - М.: Аспект-Пресс, 2003. - 286 с.

8. Михеева С. А. Рациональность и экононическое поведение: междисциплинсрный подход. //В кн. Профессиональное самосознание и экономическое поведение личности: Труды международной научной интернет-конференции. Киев.: Простобук, 2011, c. 36-47.

https://publications.hse.ru/chapters/134289638 (18.12.2021)

9. Нейман Дж., Моргенштерн О. Теория игр и экономическое поведение». - М.: «Наука», 1970. - 708 с.

10. Пасыпанова О. С. Экономическая психология: психологические аспекты поведения потребителей. // Монография.-Калуга: Изд-во КГУ им. К.Э. Циалковского, 2012, 296 с.

11. Шабунова А. А., Белехова Г. В. Экономическое поведение населения: теоретические аспекты / Перепринт.- Вологда: ИСЭР PAH, 2012. - 136 c.

12. Katona George (1951). "Psychological Analysis of Economical Behavior". B.Y., McGraw-Hill, 347 p.

13. Rabin M. Psychology and Economics // Journal of Econ. Lit. 1998, V. 36, No. 1, pp. 11-46. http://www.e-jel.org/archive/mar1998/Rabin.pdf. (19.12.2021)

14. Taflinger R. (2011). Taking Advantage: Consumer Psychology and Advartising. Kendall Hunt Publishing; 1 st edition. 160 p.

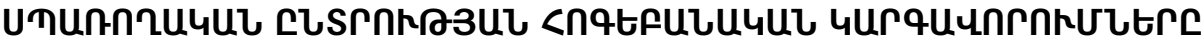 uఒah sustuuuul yurentu}

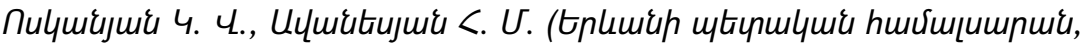
tpluши, <щлшичиші)

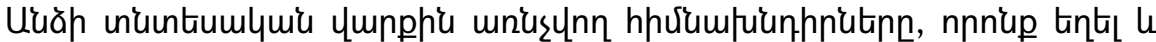

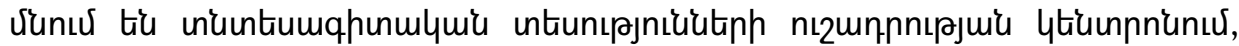

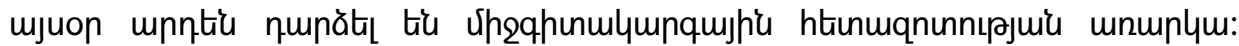

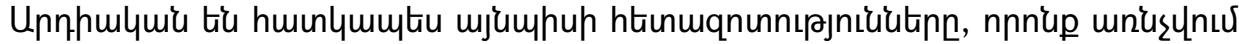

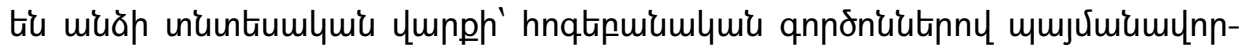

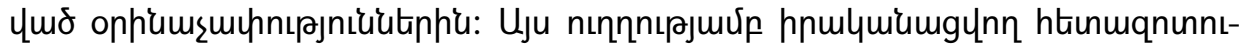




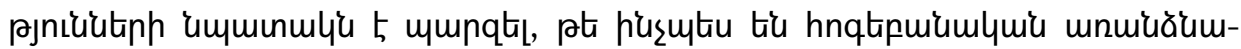

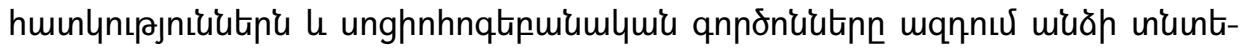

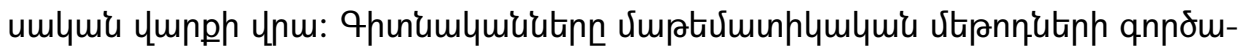

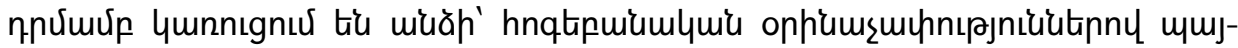

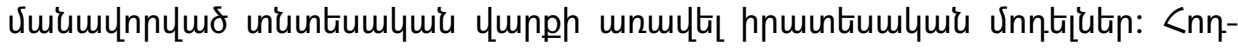

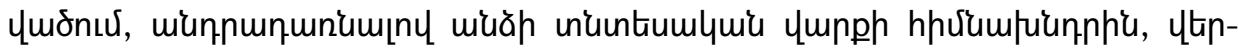

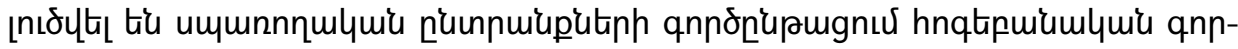

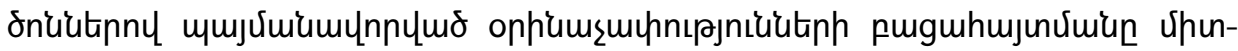

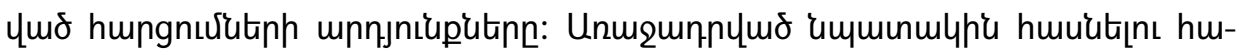

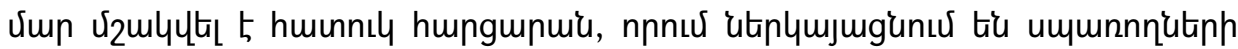

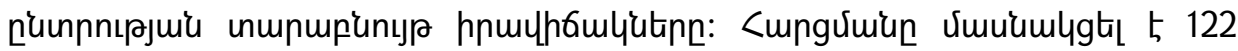

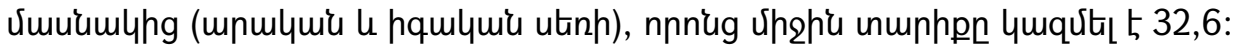

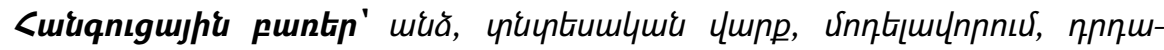

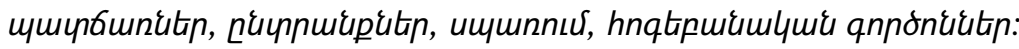

\section{ПСИХОЛОГИЧЕСКИЕ ЗАКОНОМЕРНОСТИ ПОТРЕБИТЕЛЬСКОГО ВЫБОРА В ЭКОНОМИЧЕСКОМ ПОВЕДЕНИИ ЛИЧНОСТИ}

Восканян К. В., Аванесян Г.М.(Ереванский государственный университет, Ереван, Армения)

В статье рассматривается проблема экономического поведения личности, и анализируются результаты опроса, направленного на выявление закономерностей, обусловленных психологическими факторами в процессе выбора. Для реализации поставленной цели был разработан специальный вопросник, в котором представлены различные ситуации потребительского выбора. В опросе участоввало 122 репондентов, средний возраст которых составил 32,6. Это позволило оценить особенности принятия решений при некоторой неопределенности. Вопросы, связанные с экономическим поведением личности, которые всегда были и остаются в центре внимания экономической теории, преобрели характер междисциплинарных исследований. Особенно актуальны исследования закономерностей экономического поведения, которое во многом обусловленно психологическими фракторами. Ученые, все чаще используя математические методы, строят более реалистичные модели экономического поведения личности. В исследованиях этого направлении ставится цель выяснить, как психологические характеристики и социально-психологические фракторы влияют на экономическое поведение личности.

Ключевые слова: экономическое поведение, личность, моделирование, мотивы, выбор, потребление, психплогические факторы. 